\title{
C-axis Oriented ZnO Piezoelectric Thin Films Prepared by RF Magnetron Sputtering for Saw Filters
}

\author{
Weihua Huang \\ Department of Electrical Engineering \\ Guangxi Technological College of Machinery and Electricity \\ Nanning 530007, China
}

\begin{abstract}
Well-crystallized ZnO thin film with high (002) orientation was prepared by $R F$ magnetron sputtering on $\mathrm{Pt} / \mathrm{Ti} / \mathrm{SiO} 2 / \mathrm{Si}$ substrates. Interdigital transducer (IDT) electrode with $40 \mu \mathrm{m}$ wavelength was fabricated by lift-off method based on photolithograph techniques. The thickness of the Al electrode was about $200 \mathrm{~nm}$. The orientation of the film was studied using $\mathrm{X}$-ray diffraction. The surface morphology was investigated using scanning electron microscopy (SEM). SAW filter was measured by Network Analyzer. To improving the quality of $\mathrm{ZnO}$ film and the property of SAW filter, Mn-doped ZnO films were deposited and the structural and electrical properties of the films han been characterized.
\end{abstract}

Keywords-ZnO films, SAW, lift-off, IDT

\section{INTRODUCTION}

$\mathrm{ZnO}$ is a direct wide bandgap (about $3.3 \mathrm{eV}$ ) semiconductor with the hexagonal crystal structure. And $\mathrm{ZnO}$ is a versatile material for many applications due to its structural, electrical and optical properties. Especially, it can be used for making low-loss surface acoustic wave (SAW) filters operating at high frequency because of the high piezoelectric coupling coefficients. Compared with single-crystal substrate based SAW filters, high quality piezoelectric thin film based SAW filters lead to low power consumption, reduction of cost and circuit miniaturization through integration with mainstream MMIC technology. The study of piezoelectric thin film materials like $\mathrm{ZnO}$ will accelerate the development of future wireless communication.

Many deposition techniques have been employed for $\mathrm{ZnO}$ thin film deposition, including sputtering[1], sol-gel[2], and pulse laser deposition[3]. Among all, RF magnetron sputtering has many advantages, such as low substrate temperature, large area deposition, good adhesion of films on substrates and so on. The sputtering technique, which has been used for high quality orientation growth of various semiconductors and oxides, is the ideal production technology for growth of (002) orientation $\mathrm{ZnO}$ thin films. In this paper, (002) orientation $\mathrm{ZnO}$ thin films with high quality was fabricated by RF magnetron sputtering, and the microstructural and SAW characteristic are presented.

\section{EXPERIMENTAL}

$\mathrm{ZnO}$ thin film was deposited in a $13.56 \mathrm{MHz}, 0-300 \mathrm{~W}$ RF magnetron sputtering system (JPG-560 II ) with $7.5 \mathrm{~cm}$ diameter cathode. $\mathrm{ZnO}$ ceramic target was prepared by the standard ceramics process with high purity $\mathrm{ZnO}(99.9 \%)$ powder. The substrate was rinsed in acetone, ethanol and distilled water with ultrasonic vibration before deposition, and the chamber was pumped to a base pressure of $1 \times 10-4$ $\mathrm{Pa}$ and then the target was pre-sputtered for at least $30 \mathrm{~min}$ in an argon atmosphere to eliminate the surface pollutions. A mixed gas of high purity oxygen (99.99 \%) and argon $(99.99 \%)$ with a ratio of $1: 2$ was used as the sputtering gas with a total pressure of $2.73 \mathrm{~Pa}$. The target-to-substrate distance was fixed at $5 \mathrm{~cm}$ and the deposition power was $120 \mathrm{~W}$. $\mathrm{ZnO}$ thin film was deposited on $\mathrm{Pt} / \mathrm{Ti} / \mathrm{SiO} 2 / \mathrm{Si}$ substrate at room temperature and then annealed at $400^{\circ} \mathrm{C}$ in an $\mathrm{O} 2$ atmosphere for 2 hours. The growth conditions were optimized initially through a series of process experiments by growing $\mathrm{ZnO}$ thin films on $\mathrm{P}-\mathrm{Si}(100)$ substrates. At the above conditions, well-crystallized (002) orientation $\mathrm{ZnO}$ thin film, with high quality for SAW filter, was fabricated.

The crystallinity was characterized by X-ray diffraction (XRD) operated at $35 \mathrm{KV}, 25 \mathrm{~mA}$ using $\mathrm{Cu} \mathrm{K \alpha}$ $(\lambda=1.5405 A)$ radiation. The intensity determined with $2 \theta$ from $20^{\circ}$ to $60^{\circ}$ in a 0.02 degree step size. The microstructure and the cross section were observed by field emission scanning electron microscopy (FESEM, JOEL JSM 6700F). The frequency response of the device was measured using a network analyzer.

\section{FABRICATION OF THE SAW DEVICE}

Figure 1 showed a fabrication flow chart of the SAW device. The design of IDTs was common and not weighed. The concrete processes are as follows: (1) Cleaning the substrate - clean the substrate using an organic solvent to remove the surface contamination and use de-ionized water to remove the organic particles; then dry the surface. (2) Photoresist coating - pre-bake the substrate for 2 minutes at $100^{\circ} \mathrm{C}$; spin with the photoresist and soft bake one minute at $105^{\circ} \mathrm{C}$.

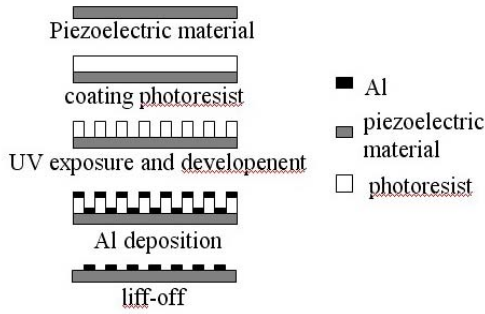

Figure 1. fabrication flow chart of the SAW devices by liff-off technology 
(3) deposure and development - expose using a mask, develop and hard bake. (4) Sputtering - after photolithography, sputter the $\mathrm{Al}$ electrode to a thickness of 200nm using RF magnetron sputtering. (5) Lift-off - dip in the acetone.

Figure 2 presened the top view IDTs photographic of the fabricated SAW device.

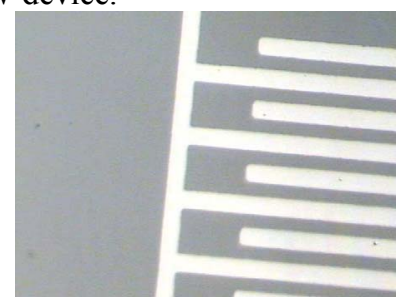

Figure 2. the top view IDTs photographic of the fabricated SAW device.

\section{RESULTS AND DISCUSSIONS}

Figure 3 showed the XRD pattern of $\mathrm{ZnO}$ thin film fabricated on $\mathrm{Pt} / \mathrm{Ti} / \mathrm{SiO} 2 / \mathrm{Si}$ substrate at room temperature and annealed at $400{ }^{\circ} \mathrm{C}$ in $\mathrm{O} 2$ atmosphere. It's obvious that the film exhibit only two peaks around $34.4^{\circ}$ and $40^{\circ}$, related to (002) plane of hexagonal phase and Pt (111) peak, respectively. It showed that the $\mathrm{ZnO}$ thin film exhibited a strong preferential (002) orientation. The FWHM of the $34.4^{\circ}$ peak was only $0.34^{\circ}$, indicating that the $\mathrm{ZnO}$ thin film was well-crystallized.

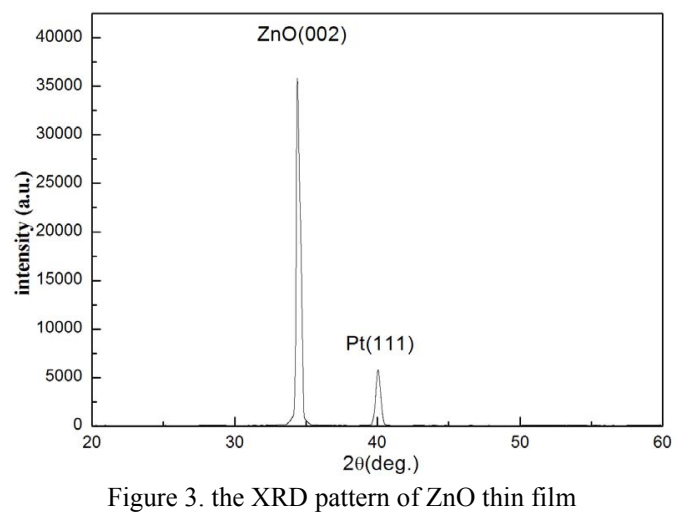

Figure 4 was the SEM spectra of the $\mathrm{ZnO}$ thin film. It can be seen, from the surface micrograph, that the grain of the $\mathrm{ZnO}$ film was spheric, and the grain size was small and uniform. There was no visible pores and defects over the film. In addition, the surface was smooth and densely packed. It's can be observed, from the cross-section image, that the $\mathrm{ZnO}$ film had a columnar crystal structure, indicating that the film had been crystallized and exhibited c-axis preferential growth characteristic. A dense interface structure also can be observed, indicating strong interface bonding.

Figure 5 showed the 3D AFM image for $\mathrm{ZnO}$ film grown on $\mathrm{Pt} / \mathrm{Ti} / \mathrm{SiO} 2 / \mathrm{Si}$ substrate at room temperature and annealed at $400{ }^{\circ} \mathrm{C}$ in $\mathrm{O} 2$ atmosphere. The image indicated that the film grew with densely packed columnar structures, as can be seen in Figure 3. The surface root-mean-square roughness (rms) is $7.78 \mathrm{~nm}$, showing smooth surface structure of the $\mathrm{ZnO}$ film. (a)

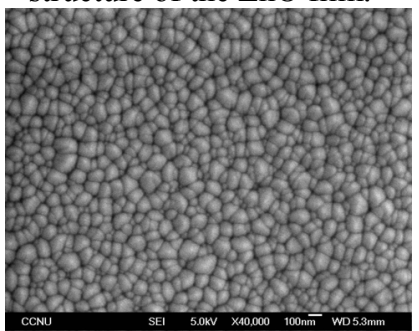

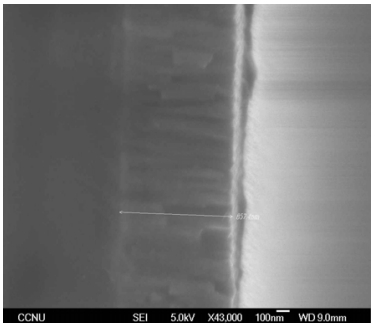

(b)
Figure 4. the SEM spectra of the $\mathrm{ZnO}$ thin film (a) surface morphology (b) cross-section image

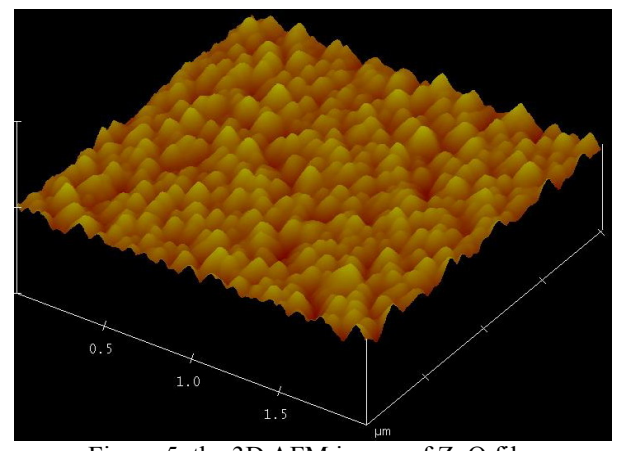

Figure 5. the 3D AFM image of $\mathrm{ZnO}$ film

The center frequency of a conventional SAW filter is determined by the width of the IDT finger and the phase velocity which excite the SAW on the piezoelectric materials.

$$
V_{s}=\lambda f=(4 d) f
$$

Where Vs is the phase velocity of the SAW, $\lambda_{\text {is the }}^{(1)}$ wavelength of the SAW, $\mathrm{f}$ is the center frequency of the SAW filter and $d$ is the one finger width of IDT. In our study, the one finger width of the IDT is $10 \mu \mathrm{m}$, so the wavelength of the SAW filter is $40 \mu \mathrm{m}$, the center frequency of $146.8 \mathrm{MHz}$ can be seen from the frequency response of the SAW filter, showing in the Figure 6 . So according to the formula (1), the phase velocity of the SAW is about $5872 \mathrm{~m} / \mathrm{s}$. Thus, the SAW filter with a center frequency of GHz can be fabricated on the $\mathrm{ZnO} / \mathrm{Pt} / \mathrm{Ti} / \mathrm{SiO} 2 / \mathrm{Si}$ by using advanced $0.13 \mu \mathrm{m}$ ULSI technology.

\section{MN-DOPED ZNO FILM}

As can be seen in Figure6, the insertion loss was large and the bandwidth was narrow of that SAW device fabricated using pure $\mathrm{ZnO}$ thin film. To improve the frequency performance of the device, $0.1 \mathrm{wt} \%$ and $4 \mathrm{wt} \%$ Mn-doped $\mathrm{ZnO}$ thin films was faricated by $\mathrm{RF}$ magnetron sputtering and the structural and electrical properties were studied.

Figure7 showed the XRD pattern of Mn-doped $\mathrm{ZnO}$ thin films fabricated on $\mathrm{Pt} / \mathrm{Ti} / \mathrm{SiO} 2 / \mathrm{Si}$ substrate at room temperature and annealed at $400{ }^{\circ} \mathrm{C}$ in $\mathrm{O} 2$ atmosphere. It's 
obvious that $0.1 \mathrm{wt} \% \mathrm{Mn}$-doped $\mathrm{ZnO}$ film exhibit only one peak around $34.4^{\circ}$, related to (002) plane of hexagonal phase. It showed that the film exhibited a strong preferential (002) orientation and was well-crystallized. On the other hand, $4 \mathrm{wt} \% \mathrm{Mn}$-doped $\mathrm{ZnO}$ film exhibit two other peaks around $32^{\circ}$ and $56^{\circ}$, related to $\mathrm{ZnO}(100)$ and $\mathrm{MnO} 2(402)$ peak, respectively. It's probably because when $\mathrm{MnO} 2$ largely doped into $\mathrm{ZnO}$, some $\mathrm{MnO} 2$ gathered at the grain boundary. So $4 \mathrm{wt} \% \mathrm{Mn}$-doped $\mathrm{ZnO}$ film was poor-crystallized and the preferential (002) orientation was damaged. Comparing the XRD results, $0.1 \mathrm{wt} \% \mathrm{Mn}$-doped Zno film was better than $4 \mathrm{wt} \% \mathrm{Mn}$-doped $\mathrm{ZnO}$ film for SAW device, concequently, the electrical characteristic of $0.1 \mathrm{wt} \% \mathrm{Mn}$-doped $\mathrm{ZnO}$ film was further studied.

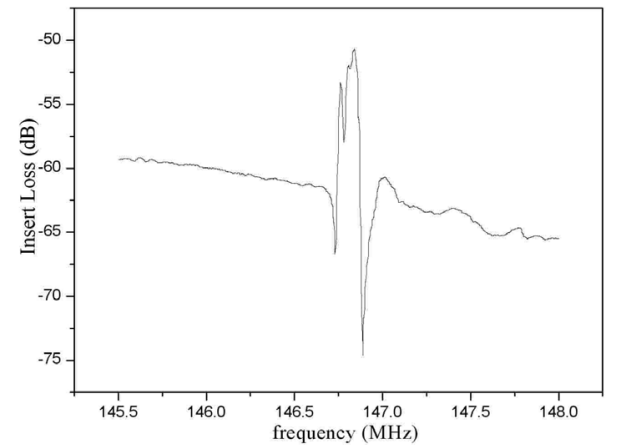

Figure 6. the frequency response of the SAW filter

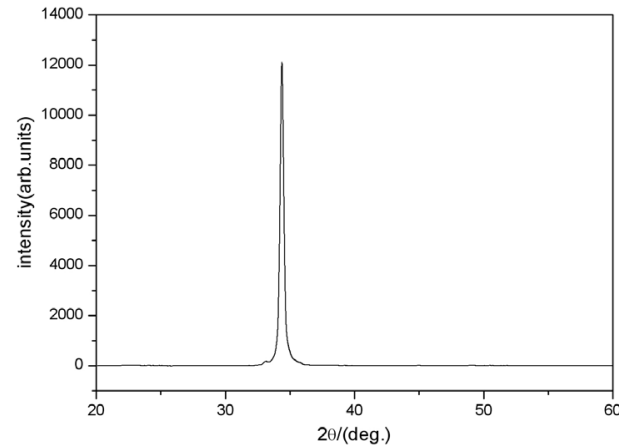

(a)

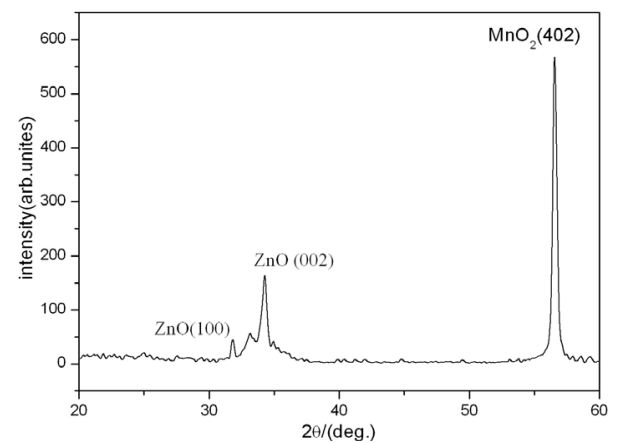

(b)

(a) $0.1 \mathrm{wt} \% \mathrm{Mn}-$ doped, (b) $4 \mathrm{wt} \% \mathrm{Mn}-$ doped

Figure 7. XRD patterns of Mn-doped $\mathrm{ZnO}$ films

Figure 8 showed the I-V curves of pure and $0.1 \mathrm{wt} \%$ Mn-doped $\mathrm{ZnO}$ film. To facilitated comparison, the thickness and the top electrode area of $0.1 \mathrm{wt} \%$

$\mathrm{Mn}$-doped $\mathrm{ZnO}$ film was the same as the pure one. It showed that the leakage current was sharply decreased when doped with $\mathrm{Mn}$. The applied voltage varies from 0 to $5 \mathrm{~V}$, the leakage current of $0.1 \mathrm{wt} \% \mathrm{Mn}$-doped $\mathrm{ZnO}$ film was smaller and kept at about 10-13 order of magnitude. When the applied voltage increases above $4 \mathrm{~V}$, the leakage current increases rapidly but still kept at about 10-9 order of magnitude.

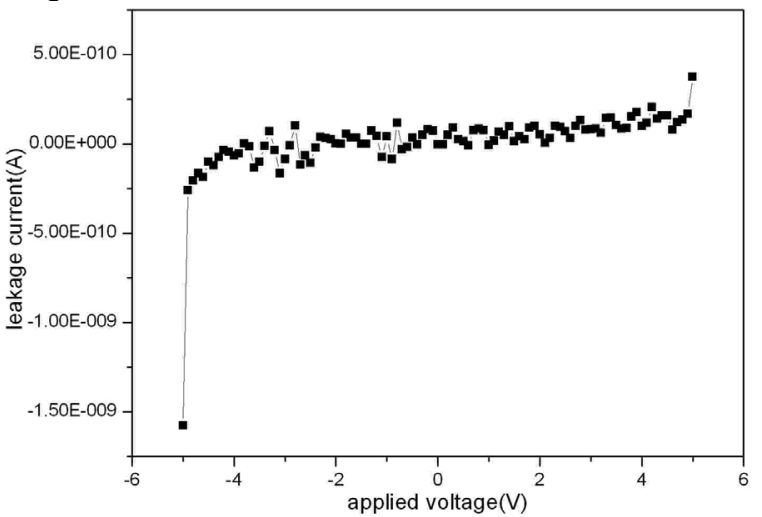

(a)

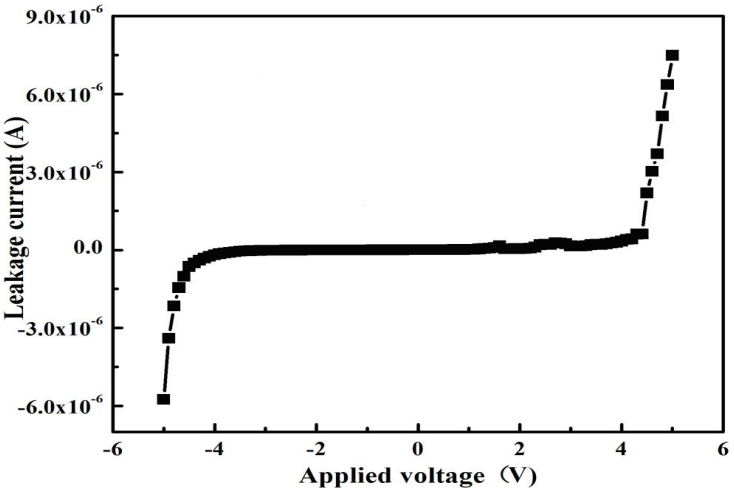

(b)

(a) $0.1 \mathrm{wt} \% \mathrm{Mn}$-doped $\mathrm{ZnO}$ film, (b) pure $\mathrm{ZnO}$ film

Figure 8 . I $-\mathrm{V}$ curves of pure and $0.1 \mathrm{wt} \% \mathrm{Mn}$-doped $\mathrm{ZnO}$ films

$\mathrm{ZnO}$ thin film is n-type semiconductor, and the electric conductivity was relevant on the oxygen vacancies and interstitial zinc atoms. When doped with $\mathrm{Mn}$, the migration rate of oxygen vacancies in grain boundary decreased, on the contrary the barrier of grain boundary increased. Therefore, the resistance of the film increase.

\section{SUMMARIES}

$\mathrm{C}$-axis orientated $\mathrm{ZnO}$ thin film was prepared by $\mathrm{RF}$ magnetron sputtering on $\mathrm{Pt} / \mathrm{Ti} / \mathrm{SiO} 2 / \mathrm{Si}$ substrates. And the SAW filter was also fabricated with the wavelength of $40 \mu \mathrm{m}$. The structural of $\mathrm{ZnO}$ thin film and the frequency response of the SAW filter was studied. The XRD result revealed that the $\mathrm{ZnO}$ thin film was strong $\mathrm{C}$-axis oriented, and well-crystallized. The SEM images indicated that the surface of the $\mathrm{ZnO}$ thin film was smooth and densely packed, and the growth of the $\mathrm{ZnO}$ film had a columnar crystal structure. 
The frequency response of the filter indicated that the center frequency of the device was $146.8 \mathrm{MHz}$ and the phase velocity of the SAW was $5782 \mathrm{~m} / \mathrm{s}$. When doped with $\mathrm{Mn}$, the stuctural and electrical properties of film were impoved and higher frequency SAW device can be achieved and used in practice by $0.1 \mathrm{wt} \% \mathrm{Mn}$-doped $\mathrm{ZnO}$ film in the future.

\section{REFERENCES}

[1] Lisa J.Wang; Gregory J.Exarhos. Persistent conductivity in post-growth doped $\mathrm{ZnO}$ films following pulsed UV laser irradiation. Thin Solid Films[J], 2010, PP:1495-1500

[2] Zhang Can-yun. High-quality oriented $\mathrm{ZnO}$ films grown by sol-gel process assisted with $\mathrm{Zn}$ seed layer. Journal of Physics and Chemistry of Solids[J], 2010, PP:364-369

[3] X.Q.Wei; Z.Zhang; Y.X.Yu; B.Y.Man.Comparative study on structural and optical properties of $\mathrm{ZnO}$ thin films prepared by PLD using $\mathrm{ZnO}$ powder target and ceramic target. Optics \& LaserTechnology[J], 2009, PP:530-534 